Table 1 also gives the values of $s b$ for the inner ring, which have a spread of $\pm 5 \cdot 3$ per cent about the median value of $1 \cdot 22$. The spread may result in part from uncertainties in the calibration of the patterns, which was dono from the actual specimen when cooled or when fully developed. With curve $a$ the calibration is from the crystalline phase at an unknown temperature difference from the melt; and in all the curves the lattice spacing value of the calibration may differ slightly from the value taken, that of bulk metal. The important point, however, is the similarity of the profiles.

$\begin{array}{ccc}\text { Table 1. VALTES OF } b \text { ANI OF } s b \text { FOR THE INNER RING } \\ \text { Specinen } & b\left(20^{\circ} \mathrm{C}\right)^{8} & s b \\ a & (\AA) & 1.15 \\ b & 3 \cdot 50 & 1.24 \\ a & 2 \cdot 89 & 1.28 \\ d & 2 \cdot 49 & 1.16\end{array}$

Since scattering differential cross-sections of this form are observed in the initial stages of film growth of many face-centred cubic motals and a number of body-centred inetals, one may therefore conclude that the earliest stage of nucleation of metals on to amorphous substrates is clusters of atoms which are amorphous in the strict sense of the disorder characteristic of monatomic liquids.

Engineering Laboratory,

C. W. B. Grigson

Cambridge.

Recelved November 23. revised December 16, 1966.

${ }^{2}$ Grigson, C. W. B., Dove, D. B., and Stilwell, G. R., Nature, 204, 173 (1964).

${ }^{2}$ Denbigh, P. N., and Marcus, R. B., J. App. Phys., 37, 4325 (1966).

${ }^{3}$ Germer, L. R., and White, A. H., Phys. Rev., 60, 447 (1941).

- Debye, P., Ann. Phys., 46, 809 (1915).

Grigson, C. W. B., and Dove, D. B., J. Vac. Science and Technol., 3, 120 (1966).

- Grigson, C. W. B., and Barton, E., Brit. J. App. Phys. (in the press).

'For review sce Furukawa, K., Rep. Prog. Phys, 25, 396 (1963).

${ }^{8}$ Heidenreich, R. D., Fundamentals of Transmission Electron Microscopy, 368 (Interscience. London, 1964).

\section{CHEMISTRY \\ Effect of Moisture on Liesegang Ring Formation in Ammonia-Hydrogen Chloride System}

If ammonium chloride is formed by counter-current diffusion of ammonia and hydrogen chloride gases in a long tube, periodic precipitation of the product in the form of rings is observed. This phenomenon has been explained by considering that nucleation and deposition of the product occur only when conditions of supersaturation exist, that is, when the concentration product of the reactants greatly exceeds the solubility product of ammonium chloride. By using this concept of supersaturation, Wagner ${ }^{1}$ has developed a mathematical model which accounts for the formation of the "Liesegang rings" and which predicts accurately the frequency and separation of the rings.

Uncertainty arises, however, as to the importance of the presence of water vapour in the nucleation of the solid and formation of the rings. Hedges ${ }^{2}$ predicted that Liesegang rings could be formed in this system in the absence of water vapour, while Johnston and Manno ${ }^{3}$ expreased a contrary opinion. Spotz and Hirschfelder ${ }^{4}$ generated the ammonia and hydrogen chloride from their aqueous solutions and postulated that nuclei were formed in the gas by clusters of reactant molecules of not less than a certain critical size, approximating to $100 \mathrm{~mole}$ cules. Reaction betweon the molecules in the cluster was assumed to occur instantaneously.

We have investigated the effect of water vapour on the formation of Liesegang rings and its effect on the particle size distribution of the product formed. Initially, the reaction of ammonia and hydrogen chloride under moisture free conditions was investigated. The gases were passed through calcium chloride or phosphorous pentoxide

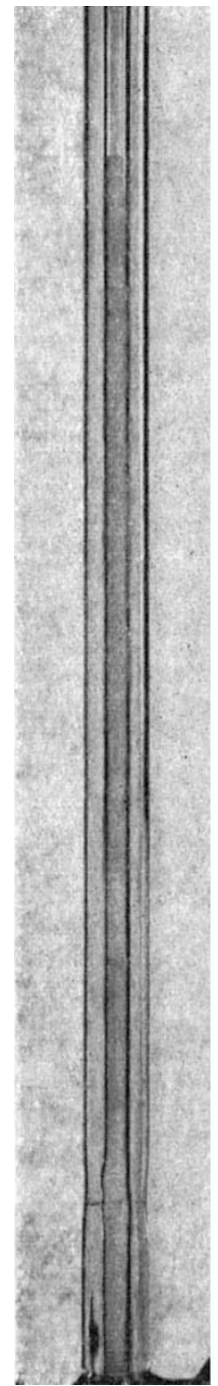

$a$
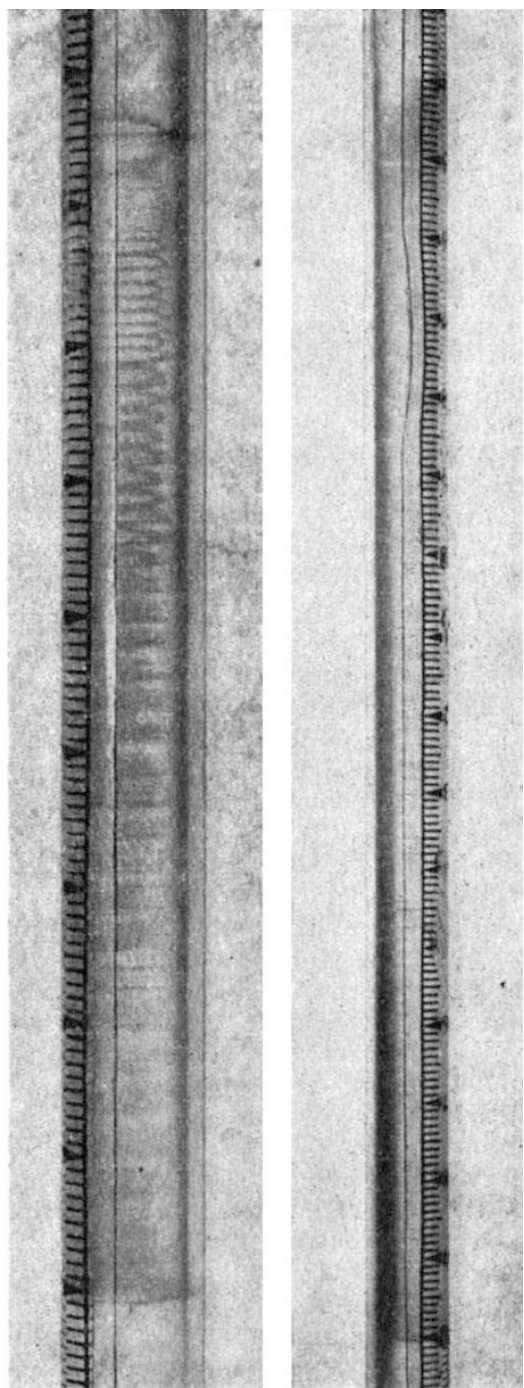

Fig. 1. a Counter diffusion of $5 \cdot 12$ per cent dry hydrogen chloride in nitrogen and 4.95 per cent dry ammonia in nitrogen in a $6-\mathrm{mm}$ glass tube after exposure to air at $25^{\circ} \mathrm{C}, 75$ per cent humidity. $b$ and $c$. Liesegang rings formed by the interaction of ammonia and hydrogen chloride vapours in equilibrium with aqueous solutions at $30^{\circ} \mathrm{C}$. $b, 12 \cdot 26$ per cent $w / w$ ammonia with $36 \cdot 15$ per cent $w / w$ hydrogen chloride in an 8-mm glass tube. $c, 14.91$ per cent $w / w$ ammonia with 36.15 per cent $w / w$ hydrogen chloride in a $6-\mathrm{mm}$ glass tube.

and molecular sieves. No Liesegang rings were formed, but when the tube was opened to a controlled atmosphere containing water vapour rings were successively formed as the water vapour diffused along the tube (Fig. 1a).

In the second series of experiments where the reacting gases contained water vapour, Liesegang rings formed along the tube (Fig. $1 b$ and $c$ ) and the ring frequency and separation were in agreement with those predicted from Wagner's theory. The presence of water vapour is therefore essential for nucleation of the ammonium chloride and forma. tion of Liesegang rings in this system.

G. A. Davies

A. B. Ponter

S. SingH

Department of Chemical Engineering, University of Manchester Institute of Science and Technology.

1 Wagner. C., J. Colloid Sci., 5, 85 (1950).

Hedges, E. S., Liesegang Rings and Other Periodic Structures (Chapman and Hall, London, 1932).

Johnston, W. H., and Manno, P. J., Indust. Eng. Chem., 44, 1304 (1952).

Spotz, E. L., and Hirschfelder, J. O., J. Chem. Phys., 19, 1215 (1951). 